\title{
Is Duhuo Jisheng Tang containing Xixin safe? A four-week safety study
}

\author{
Shu-Ching Hsieh ${ }^{1,2}$, Jung-Nien Lai ${ }^{3,4}$, Pau-Chung Chen ${ }^{2}$, Chao-Chung Chen ${ }^{5}$, Huey-Jen Chen ${ }^{6}$, Jung-Der Wang ${ }^{2,7,8^{*}}$
}

\begin{abstract}
Background: Though the nephrotoxicity and carcinogenicity of aristolochic acid (AA) are known, its safety in clinical usage is not clear. This study aims to evaluate the safety of Duhuo Jisheng Tang (DJT) in a four-week study to treat osteoarthritis $(\mathrm{OA})$ of the knee.

Methods: A qualitative and quantitative investigations on DJT were conducted. A list of adverse events (AEs), complete blood counts, and liver and kidney function tests were measured for participants with knee OA at their scheduled hospital visits. Each detected AEs was independently assessed for severity and causality by site investigators (Chinese medical doctors) and study nurses.
\end{abstract}

Results: A total of 71 eligible subjects were included in the clinical study where 287 AEs were reported. DJT did not contain detectable aristolochic acid (AA) under thin-layer chromatography (TLC) analysis and gas chromatography coupled with mass spectrometry (GC-MS). There were no significant changes in liver or kidney functions.

Conclusion: In four-week use of DJT, no renal tubular damage, no severe incidences of AEs and adverse drug reactions (ADRs) were observed. The present study obtained safety data from active surveillance of DJT.

\section{Background}

While medicinal herbal products are widely used $[1,2]$ with a presumption that natural herbs are safe, there is a lack of safety evidence to support such products. Since the discovery of nephrotoxicity and carcinogenicity of aristolochic acid (AA) [3-5], the International Agency for Research into Cancer (IARC) has considered herbal remedies containing plants of aristolochia genus as Group 1 human carcinogens and those containing naturally occurring mixtures of AAs as 2A carcinogens [6]. Medicinal plants that contain AAs are banned in certain countries, including USA, UK, Canada, and Taiwan $[7,8]$.

Xixin (Radix et Rhizoma Asari), also known as Saishin in Japan or Sesin in Korea, is widely used in many parts of Asia despite that it contains AAs [9-11]. For example, since 2004, a total of 393 Chinese herbal products (CHPs) containing Xixin have been reimbursed under the National Health Insurance (NHI) in Taiwan [12] where the regulations stipulate that AA must be

\footnotetext{
* Correspondence: jdwang@ntu.edu.tw

${ }^{2}$ Institute of Occupational Medicine and Industrial Hygiene, College of Public Health, National Taiwan University, Taipei 100, Taiwan
}

undetectable in final herbal products [13]. Our preliminary analysis of NHI data found that about 1.57 million in Taiwan have been prescribed with CHPs containing Xixin. Duhuo Jisheng Tang (DJT), an herbal formula described by the ancient Chinese physician Sun Simiao in $652 \mathrm{AD}$ to treat low back/knee pain [14-16], was prescribed to 725,549 patients between 1996 and 2004. DJT was attributed to AA-related nephropathy in a case report [17].

In another aspect, many clinical trials of Chinese herbal medicines (CHMs) have been rated as having poor methodological quality [18], though CHMs is regarded by the World Health Organization (WHO) as in the urgent need to establish evidence-based information [19]. The active monitoring of safety profile demonstrated in our previous study is proved useful to supplement the current pharmacovigilance function [20]. Therefore, the present study aims to determine whether AA is present in Xixin-containing CHPs such as DJT and whether DJT use causes acute nephrotoxicity by qualitative and quantitative methods incorporated in active safety surveillance system. The results of efficacy evaluation were reported in a separate paper [21]. 


\section{Methods \\ DJT preparation}

The investigational DJT was supplied by Sun Ten Pharmaceutical Company (Taiwan) in a standardized form of 15 concentrated herbal extracts, namely Duhuo (Radix Angelicae Pubescentis), Qinjiao (Radix Gentianae Macrophyllae), Fangfeng (Radix Saposhnikoviae), Xixin, Rougui (Cortex Cinnamomi), Sangjisheng (Herba Taxilli), Duzhong (Cortex Eucommiae), Shudihuang (Radix Rehmanniae), Niuxi (Radix Cyathulae), Danggui (Radix Angelicae Sinensis), Baishao (Radix Paeoniae Alba), Chuanxiong (Rhizoma Chuanxiong), Renshen (Radix et Rhizoma Ginseng), Fuling (Poria) and Gancao (Radix et Rhizoma Glycyrrhizae). The final product is $2.5 \mathrm{~g}$ of granules packed in a sachet.

The investigational DJT, three other brands of each of DJT and Xixin were produced by pharmaceutical companies with good manufacturing practice (GMP) certification. All samples were sent to the Bureau of Food and Drug Analysis of Taiwan for chemical analysis. Thinlayer chromatography (TLC) and gas chromatography coupled with mass spectrometry (GC-MS) were used to confirm Xixin in these samples by identifying their characteristic peaks of Asarinin. High-performance liquid chromatography (HPLC) and liquid chromatography coupled with tandem mass spectrometer (LC/MS/MS) were then carried out to detect AA in these samples [22].

A clinical study with active safety surveillance [20] on detection and causality assessment of adverse events (AEs) was launched at the Yangming and Chinese Medicine Branches of Taipei City Hospital. This study was approved by the Joint Institutional Review Board for Traditional Chinese Medicine, and received regular external monitoring and auditing by a third Research Organization during the study period.

\section{Inclusion and exclusion criteria for study subjects}

Adult patients with osteoarthritis in at least one knee in the previous six months were recruited for the study. Exclusion criteria are as follows: (1) intra-articular injections of non-steroidal anti-inflammatory drugs within one month; (2) secondary arthritis related to syphilitic neuropathy, ochronosis, metabolic bone disease or acute trauma, severe osteoporosis ( $\geq$ grade 3) [23] or acute rheumatic arthritis; (3) significant co-morbidities, such as hypertension, severe hepatitis, kidney diseases or malignant carcinoma; (4) spinopathy caused by tumor (benign or malignant); (5) the use of any other investigational drugs within the past 30 days; (6) women with childbearing potential who had not used adequate contraception since their last menstruation or would not continuously use adequate contraception during the study period; and (7) women who were lactating or positive in a urine pregnancy test within 14 days prior to the study. Quota for recruiting participants from Yangming and Chinese Medicine Branches of Taipei City Hospital was 40. All recruited subjects were required to sign an informed consent form and to discontinue any form of treatment and current medications, including western medicine and CHPs, at least two weeks prior to the screening for the study.

\section{Active surveillance for safety}

A surveillance list of 20 pre-hypothesized AEs was compiled with spaces allowed for AEs not in the list. The AE-specific form with the description of the signs and symptoms was used to ask subjects questions for causality information [24], including necessary criteria (temporality), quasi-necessary criteria (consistency, chance elimination and confounders as alternative explanations and coherence with other highly corroborated theories) and other supportive criteria (e.g. strength and specificity of association, dose response relationship and biological plausibility). The information on every reported $\mathrm{AE}$ was collected in respective structured forms for causality assessment. Through a prospective design, we collected the quantitative and qualitative data related to each $\mathrm{AE}$ and looked for possible explanation during each incidence. Moreover, we adopted a consensual approach to minimize disagreements and reach a more credible conclusion in causality assessment for AE-drug combinations $[25,26]$.

The recruited subjects were required to take two sachets $(5 \mathrm{~g})$ of the investigational DJT per day for four weeks, an adequate treatment course estimated by the clinicians for the measurement of DJT efficacy and for the detection of early tubular damage to the kidney. Laboratory tests were conducted at baseline visit and four weeks after taking DJT, including routine urinalysis, complete blood and platelet counts, biochemistry measures and urinary $\mathrm{N}$-acetyl-glucosaminidase (NAG) and retinal binding protein (RBP) $[27,28]$.

Every detected/reported AE was independently assessed by onsite investigators (Chinese medical doctors) and study nurses. The investigators applied unstructured clinical judgment [29] to rate the AEs severity as mild (transient or mild discomfort; no medical intervention required), moderate (some assistance needed; no medical intervention required) or severe (marked limitation in activity; medical intervention required and possible hospitalization); and rate the AEdrug causality as uncertain, probable/likely, possible, unlikely, conditional/unclassified and unassessable/ unclassifiable [30]. The study nurses adopted the Common Terminology Criteria for Adverse Events (CTCAE) v3.0 [31] to judge the severity of the AEs and Naranjo 
scale [32] to assess causality. Any severe AEs, or any AEs judged to be highly correlated to DJT was be submitted to the research panel for final decision.

\section{Data analysis}

The data were analyzed using simple statistics. The outcome variables were the incidence rates of AEs and adverse drug reactions (ADRs), which were calculated by dividing the event counts of the AEs and ADRs (the numerator) by the exposure level, in terms of persondays or person-sachets (the denominator). The former was the total number of all the participants' exposed (intend-to-treat) person-days to the study drug, while the latter was the actual number of sachets which participants had taken during the study period.

\section{Results}

Laboratory tests

TLC results revealed that seven samples contained Xixin. GC-MS results also confirmed Asarinin, the main component of Xixin. LC/MS/MS or HPLC detected AAI and AAII only in the three brands of Xixin samples when those were condensed 25 times (Table 1).

\section{Subjects}

A total of 87 subjects who signed the informed consent form were screened. Sixteen subjects did not receive

Table 1 Detection of aristolochic acid (AA) in study drug and other brand products in the market

\begin{tabular}{|c|c|c|c|}
\hline \multirow[b]{2}{*}{ Chinese herbal products } & \multirow[b]{2}{*}{ Sample no. } & \multicolumn{2}{|c|}{ Contents $(\mu \mathrm{g} / \mathrm{g}$} \\
\hline & & $\overline{A A-I^{a}}$ & $\mathrm{AA}-\mathrm{II}^{\mathrm{a}}$ \\
\hline \multirow[t]{2}{*}{ DJT (study drug) } & 1 & $(-)$ & $(-)$ \\
\hline & 25-fold concentration & $(-)$ & $(-)$ \\
\hline \multicolumn{4}{|c|}{ Other brand products bought in the open market } \\
\hline \multirow[t]{2}{*}{ DJT (brand $1^{b}$ ) } & 2 & $(-)$ & $(-)$ \\
\hline & 16.7-fold concentration ${ }^{c}$ & $(-)$ & $(-)$ \\
\hline \multirow[t]{2}{*}{ DJT (brand 2) } & 3 & $(-)$ & $(-)$ \\
\hline & 25-fold concentration & $(-)$ & $(-)$ \\
\hline \multirow[t]{2}{*}{ DJT (brand 3) } & 4 & $(-)$ & $(-)$ \\
\hline & 10-fold concentration ${ }^{c}$ & $(-)$ & $(-)$ \\
\hline \multirow[t]{2}{*}{ Xixin (brand 1 ${ }^{\mathrm{b}}$ ) } & 5 & $(-)$ & $(-)$ \\
\hline & 25-fold concentration & 6.64 & $(-)$ \\
\hline \multirow[t]{2}{*}{ Xixin (brand 2) } & 6 & $(-)$ & $(-)$ \\
\hline & 25-fold concentration & 6.77 & $(-)$ \\
\hline \multirow[t]{2}{*}{ Xixin (brand 3) } & 7 & $(-)$ & $(-)$ \\
\hline & 25-fold concentration & 9.95 & $(-)$ \\
\hline
\end{tabular}

Notes:

a The detection limit of aristolochic acid I (AA-I) and aristolochic acid II (AAII) is $2.0 \mathrm{ng} / \mathrm{ml}$

${ }^{\mathrm{b}}$ Brand 1 products (samples nos. 2 and 5) were also produced by Sun Ten Pharmaceutical Company (Taiwan), but they were directly purchased from the market.

'Samples nos. 2 and 4 could only be concentrated up to less than 25 -fold during the test procedure. medication due to various reasons (Figure 1). Intent-totreat monitoring was given to all the rest of 71 subjects.

\section{Occurrences of adverse events}

None of the subjects showed any abnormality of urinalysis, creatinine or blood urea nitrogen, NAG or RBP. A total of 287 AEs were detected/reported during the study period (Additional file 1) and were coded according to the Coding Symbols for Thesaurus of Adverse Reaction Terms (COSTART) [33]. The most often reported AEs were rashes, abdominal fullness, coughs, somnolence, muscle cramps and diarrhea with the incidence rates of $14.5,12.9,12.4,11.9,10.3$, and 10.3 per 1000 person-days respectively; and 7.5, 6.9, 6.6, 6.3, 5.5, 5.5 per 1000 person-sachets respectively. All of these AEs were monitored according to the original surveillance list. No additional $\mathrm{AE}$ was found.

\section{Severity of the adverse events and association with DJT}

All recorded AEs were classified as 'mild' to 'moderate' according to the investigators (Chinese medical doctors), and as 'Grade 1' or 'Grade 2' according to the study nurses. These AEs were tolerable and did not have any significant effects on the subjects' daily activities. The probable ADRs separately detected by the investigators (Chinese medical doctors) and study nurses are summarized in Table 2.

\section{Discussion}

In the present study, AA was undetectable in the investigational DJT and three other brands of DJT, whereas the main peaks of the active ingredients (e.g. Asarinin) of Xixin were present in the samples. This result supports the regulations set by the Committee on Chinese Medicine and Pharmacy of Taiwan, which stipulates that only the root portion of Xixin can be used for herbal products, and therefore the final product should not contain any detectable AA [13]. However, care must be taken to prevent people from using raw herbs of Xixin which may contain higher levels of AA.

The possible existence of AA in DJT may pose a potential hazard to patients' health [34-37]. We attempted to indirectly estimate the average levels of AA in DJT from concentrated Xixin. As shown in Table 1 , AAI was detected only in concentrated (25 times) Xixin products. Those subjects who completed the study would have ingested a maximum daily dosage of 0.04$0.08 \mu \mathrm{g}$ of AAI, which was a total of 1.34-2.01 $\mu \mathrm{g}$ for the study period. None of these subjects showed any significant renal tubular damage.

A four-week study of Duhua Jisheng Wan [38], which has the same ingredients of DJT, also did not result in any kidney-related damage. As compared to the reported case of the AA-related nephropathy 


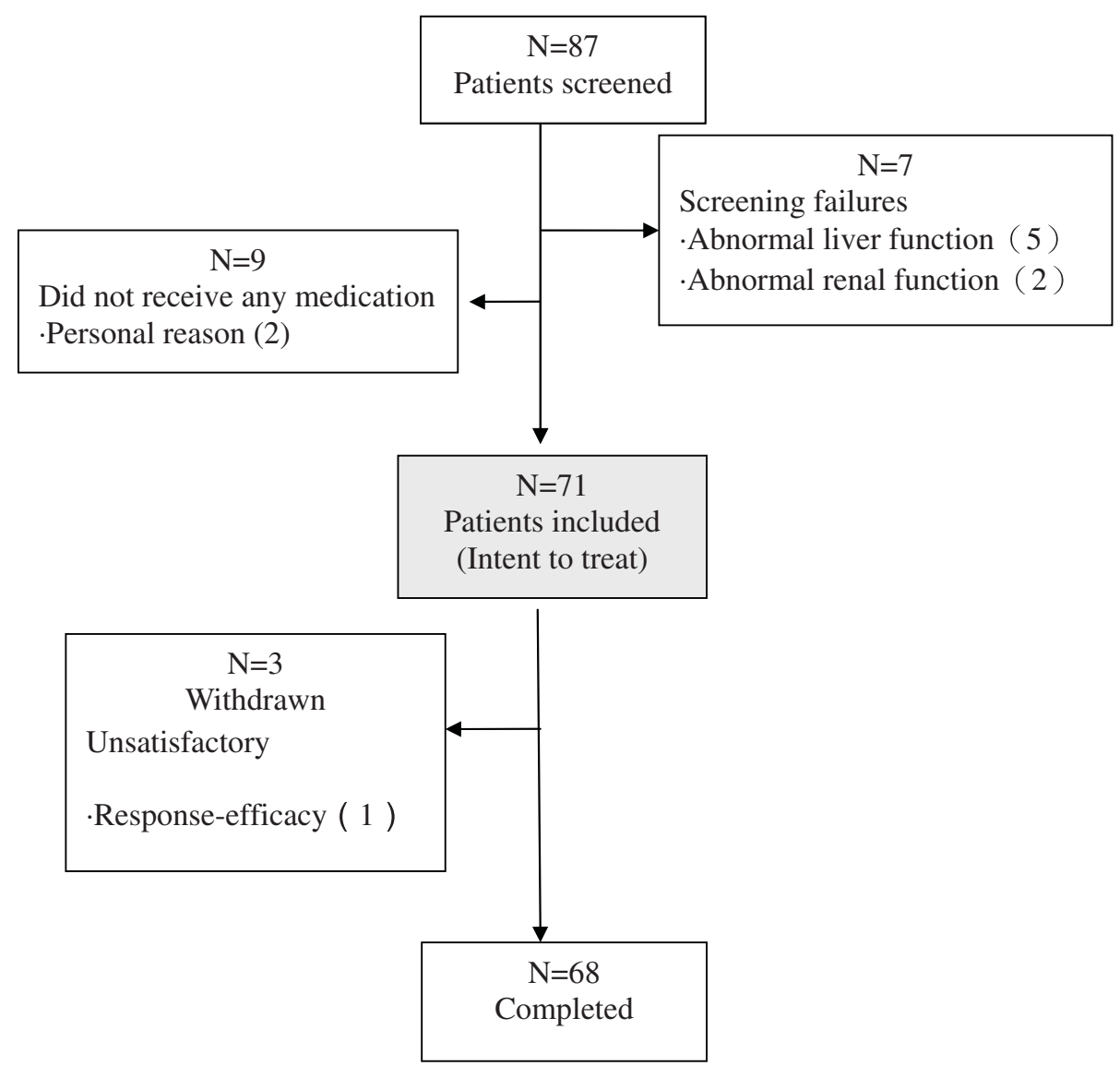

Figure 1 Recruitment of participants' inclusion, withdrawal, and completion during follow-up.

patient [17] ingesting $400 \mathrm{~g}$ of DJT powder for over four months, the ingestion levels of AA in this study were very low. However, the holistic effect stressed by CHMs theory [16] in mixing different herbs as a meaning of enhancing efficacy and minimizing toxicity cannot be completely ruled out. To evaluate the overall safety of the final DJT product as a formulated herbal preparation of 15 herbs, we list AEs for DJT in additional file 1.

The absence of a control group makes the observed results from the present study subject to potential confounders. To minimize confounders, we implemented two independent assessments by site investigators (Chinese medical doctors) and study nurses, respectively. In addition, the sample size of the present study is small.

\section{Conclusion}

In four-week use of DJT, no renal tubular damage, no severe incidence of AEs and ADRs were observed. The present study obtained safety data from active surveillance of DJT.

Table 2 Probable adverse drug reactions detected by the panel of investigators (Chinese medical doctors) and study nurses

\begin{tabular}{|c|c|c|c|c|}
\hline $\begin{array}{l}\text { Cases adjudged by the panel to } \\
\text { be probable ADRs }\end{array}$ & $\begin{array}{l}\text { Judgment by study nurses under } \\
\text { the Naranjo scale }\end{array}$ & $\begin{array}{l}\text { Subjective judgment of } \\
\text { the investigators }\end{array}$ & $\begin{array}{l}\text { Risk per } 10^{3} \\
\text { person-days }\end{array}$ & $\begin{array}{l}\text { Risk per } 10^{3} \\
\text { person-sachets }\end{array}$ \\
\hline Change in skin color & Probable & Probable/Likely & 0.5 & 0.3 \\
\hline Red flush & Probable & Certain & 0.5 & 0.3 \\
\hline Diarrhea & Possible & Probable/Likely & 0.5 & 0.3 \\
\hline Tachycardia & Probable & Unlikely & 0.5 & 0.3 \\
\hline
\end{tabular}

Notes:

${ }^{a}$ The number of cases was used as the numerator for the calculation of the risk. The denominators for the calculation of the risks were 1,936 person-days and 3,633 person-sachets. 
Additional file 1: Summary of adverse event data. Table summarizing adverse events for Duhuo Jisheng Tang.

Click here for file

[http://www.biomedcentral.com/content/supplementary/1749-8546-5-6S1.DOC]

\section{Abbreviations}

DJT: Duhuo Jisheng Tang; AA: aristolochic acid; OA: osteoarthritis; GCP: good clinical practice; AEs: adverse events; ADR: adverse drug reactions; TLC: thinlayer chromatography analysis; GC-MS: gas chromatography coupled with mass spectrometry; CHPs: Chinese herbal products; NHI: National Health Insurance; CHMs: Chinese herbal medicines; IARC: International Agency for Research into Cancer; GMP: good manufacturing practice; HPLC: highperformance liquid chromatography; LC/MS/MS: liquid chromatography coupled with tandem mass spectrometer; NAG: N-acetyl-glucosaminidase RBP: retinal binding protein; CTCAE: Common Terminology Criteria for Adverse Events; WHO: World Health Organization.

\section{Acknowledgements}

This study was supported by a grant from the Committee on Chinese Medicine and Pharmacy at the Department of Health, Executive Yuan, Taiwan (CCMP 94-CP-005). We would like to express our gratitude to all of the subjects in this study for their valuable participation and to the staff members at each of the sites and the Bureau of Food and Drug Analysis for their contributions and support.

\section{Author details}

'Division of Health Technology Assessment, Center for Drug Evaluation, Taipei 100, Taiwan. ${ }^{2}$ Institute of Occupational Medicine and Industrial Hygiene, College of Public Health, National Taiwan University, Taipei 100, Taiwan. ${ }^{3}$ Department of Obstetrics and Gynecology, Department of Chinese Medicine, Taipei City Hospital, Yangming Branch, Taipei 100, Taiwan. ${ }^{4}$ Institute of Traditional Medicine, School of Medicine, National Yangming University, Taipei 100, Taiwan. ${ }^{5}$ Division of Traumatology, Chinese Medicine Branch, Taipei City Hospital, Taipei 100, Taiwan. ${ }^{6}$ Division of Chinese Internal Medicine, Chinese Medicine Branch, Taipei City Hospital, Taipei 100, Taiwan. ${ }^{7}$ Department of Internal Medicine, National Taiwan University Hospital, Taipei 100, Taiwan. ${ }^{8}$ Department of Environmental and Occupational Medicine, National Taiwan University Hospital, Taipei 100, Taiwan.

\section{Authors' contributions}

SCH performed the study design and statistical analysis, monitored the study, and prepared the manuscript. JNL designed the study and assisted in patient recruitment with assistance from HJC and CCC. PCC conducted the statistical analysis and data interpretation. JDW conceived, designed and coordinated the study, and drafted the manuscript. All authors read and approved the final manuscript.

\section{Competing interests}

The authors declare that they have no competing interests.

Received: 15 January 2008

Accepted: 11 February 2010 Published: 11 February 2010

\section{References}

1. Eisenberg DM, Davis RB, Ettner SL, Appel S, Wilkey S, Van Rompay M, Kessler RC: Trends in alternative medicine use in the United States, 19901997: results of a follow-up national survey. JAMA 1998, 280:1569-1575.

2. Kessler RC, Davis RB, Foster DF, Van Rompay MI, Walters EE, Wilkey SA, Kaptchuk TJ, Eisenberg DM: Long-term trends in the use of complementary and alternative medical therapies in the United States. Ann Intern Med 2001, 135:262-268.

3. Cosyns JP: Aristolochic acid and 'Chinese herbs nephropathy': a review of the evidence to date. Drug Saf 2003, 26(1):33-48.

4. Arlt VM, Stiborova M, Schmeiser HH: Aristolochic acid as a probable human cancer hazard in herbal remedies: a review. Mutagenesis 2002, 17(4):265-277.
5. Nortier JL, Martinez MC, Schmeiser HH, Arlt VM, Bieler CA, Petein M, Depierreux MF, De Pauw L, Abramowicz D, Vereerstraeten P, Vanherweghem $J$ : Urothelial carcinoma associated with the use of a Chinese herb (aristolochia fangchi). N Engl J Med 2000, 342(23):1686-1692.

6. International Agency for Research on Cancer. Complete list of agents evaluated and their classification http://monographs.iarc.fr/ENG/Classification/ index.php.

7. Kessler DA: Cancer and herbs. N Engl J Med 2000, 342(23):1742-1743.

8. U.S. Food \& Drug Administration. Dietary Supplements: Aristolochic Acid http://www.fda.gov/Food/DietarySupplements/Alerts/ucm095272.htm.

9. Drew AK, Whyte IM, Bensoussan A, Dawson AH, Zhu X, Myers SP: Chinese herbal medicine toxicology database: monograph on herba asari, "xi xin". I Clin Toxicol 2002, 40(2):169-172.

10. Jong TT, Lee MR, Hsiao SS, Hsai JL, Wu TS, Chiang ST, Cai SQ: Analysis of aristolochic acid in nine sources of xixin, a traditional Chinese medicine, by liquid chromatography/atmospheric pressure chemical ionization/ tandem mass spectrometry. J Pharm Biomed Anal 2003, 33(4):831-837.

11. Hashimoto K, Higuchi M, Makino B, Sakakibara I, Kubo M, Komatsu Y, Maruno M, Okada M: Quantitative analysis of aristolochic acids, toxic compounds, contained in some medicinal plants. J Ethnopharmacol 1999, 64(2):185-189.

12. Committee on Chinese Medicine and Pharmacy, Department of Health, Executive Yuan Taiwan. Reference list of registered Chinese herbal medicines http://www.ccmp.gov.tw/public/public.asp? selno $=492 \&$ relno $=492 \&$ level $=$ C.

13. Committee on Chinese Medicine and Pharmacy, Department of Health, ExecutiveYuan Taiwan. Drug Registration-related Regulations-Xixin herbs and products http://www.ccmp.gov.tw/public/public.asp? selno $=601 \&$ relno $=601 \&$ level $=C$.

14. Committee on Chinese Medicine and Pharmacy, Department of Health, Executive Yuan Taiwan. Chinese Pharmacopoeia of Chinese Medicine http:// www.ccmp.gov.tw/public/public.asp?selno=525\&relno=525\&level=C.

15. Dharmananda, S. An Analysis of Chinese herb prescriptions for rheumatoid articles http://www.itmonline.org/arts/arthritis.htm.

16. Molony D: The American Association of Oriental Medicine's Complete Guide to Chinese Herbal Medicine New York: Berkley Books 1998.

17. Yang HY, Lin JL, Chen KH, Yu CC, Hsu PY, Lin CL: Aristolochic acid-related nephropathy associated with the popular Chinese herb Xi Xin. J Nephrol 2006, 19(1):111-114.

18. Tang JL, Zhan SY, Ernst E: Review of randomized controlled trials of traditional Chinese medicine. BMJ 1999, 319:160-161.

19. World Health Organization. WHO medicine strategy: countries at the core, 2004-2007 http://whqlibdoc.who.int/hq/2004/WHO_EDM_2004.5.pdf.

20. Hsieh SC, Lai JN, Chen PC, Chen HJ, Wang JD: Development of active safety surveillance system for traditional Chinese medicine: an empirical study in treating climacteric women. Pharmacoepidemiol Drug Saf 2006, 15(12):889-899.

21. Lai JN, Chen HJ, Chen CC, Lin JH, Hwang JS, Wang JD: Duhuo Jisheng Tang for treating osteoarthritis of the knee: a prospective clinical observation. Chin Med 2007, 2:4.

22. The Japanese Pharmacopoeia, JP XIV. General Information: Aristolochic Acid http://jpdb.nihs.go.jp/jp14e/contents.html.

23. Kellgren JH, Lawrence JS: Radiological assessment of osteo-arthrosis. Ann Rheum Dis 1957, 16(4):494-502.

24. Wang JD: Causal inference and decision. Basic Principles and Practical Applications in Epidemiological Research Singapore: World Scientific 2002, 57-79.

25. Miremont G, Haramburu F, Bégaud B, Péré JC, Dangoumau J: Adverse drug reactions: physicians' opinions versus a causality assessment method. Eur J Clin Pharmacol 1994, 46(4):285-289.

26. Arimone $Y$, Bégaud B, Miremont-Salamé G, Fourrier-Réglat A, Moore N Molimard M, Haramburu F: Agreement of expert judgment in causality assessment of adverse drug reactions. Eur J Clin Pharmacol 2005, 61(3):169-173.

27. D'Amico G, Bazzi C: Urinary protein and enzyme excretion as markers of tubular damage. Curr Opin Nephrol Hypertens 2003, 12(6):639-643.

28. Flynn FV: Assessment of renal function: selected developments. Clin Biochem 1990, 23(1):49-54.

29. Jones JK: Determining causation from case reports. Pharmacoepidemiology New York: John Wiley \& SonsStrom BL , 3 2000, 531-538. 
30. Uppsala Monitoring Center. Safety monitoring of medicinal products: guidelines for setting up and running a pharmacovigilance Center $2002 \mathrm{http}: / /$ www.who-umc.org/graphics/4807.pdf.

31. National Cancer Institute. Common Terminology Criteria for Adverse Events v3.0 http://ctep.cancer.gov/protocolDevelopment/electronic_applications/ docs/ctcaev3.pdf.

32. Naranjo CA, Busto U, Sellers EM, Sandor P, Ruiz I, Roberts EA, Janecek E, Domecq C, Greenblatt DJ: A method for estimating the probability of adverse drug reactions. Clin Pharmacol Ther 1981, 30:239-245.

33. United States Food and Drug Administration: COSTART: Coding Symbols for Thesaurus of Adverse Reaction Terms Rockville, MD: Public Health Service, Food and Drug Administration 1995.

34. Lai MN, Lai JN, Chen PC, Tseng WL, Chen YY, Hwang JS, Wang JD: Increased risks of chronic kidney disease associated with prescribed Chinese herbal products suspected to contain aristolochic acid. Nephrology 2009, 14:227-234.

35. Yang HY, Wang JD, Lo TC, Chen PC: Increased mortality risk of kidney and other urinary organs cancers in Chinese herbalists. J Epidemiol 2009, 19(1):17-23.

36. Lai MN, Wang SM, Chen PC, Chen YY, Wang JD: Population-based casecontrol study of Chinese herbal products containing aristolochic acid and urinary tract cancer risk. J Natl Cancer Inst 2010.

37. Lai MN, Lai JN, Chen PC, Hsieh SC, Hu FC, Wang JD: Risk of kidney failure associated with consumption of herbal products containing Mu Tong or Fangchi : A population-based case-control study. AJKD .

38. Teekachunhatean S, Kunanusorn P, Rojanasthien N, Sananpanich K, Pojchamarnwiputh S, Lhieochaiphunt S, Pruksakorn S: Chinese herbal recipe versus diclofenac in symptomatic treatment of osteoarthritis of the knee: a randomized controlled trial. BMC Complement Altern Med 2004, 4:19.

doi:10.1186/1749-8546-5-6

Cite this article as: Hsieh et al:: Is Duhuo Jisheng Tang containing Xixin safe?

A four-week safety study. Chinese Medicine 2010 5:6.

\section{Submit your next manuscript to BioMed Central} and take full advantage of:

- Convenient online submission

- Thorough peer review

- No space constraints or color figure charges

- Immediate publication on acceptance

- Inclusion in PubMed, CAS, Scopus and Google Scholar

- Research which is freely available for redistribution

Submit your manuscript at www.biomedcentral.com/submit
Biomed Central 